\title{
A Grand Challenge for Animal Science: Multiple Goals - Convergent and Divergent
}

\author{
Christine J. Nicol* \\ Royal Veterinary College (RVC), London, United Kingdom
}

Keywords: animal science, animal welfare, biodiversity, resource efficiency, conservation

\section{INTRODUCTION}

People want safe, affordable, high quality animal-derived foods, produced in ways that protect rural livelihoods and cultures and which are derived from animals that lived healthy and happy lives. These aspirations must be set alongside the overarching need to seek advances that reduce or eliminate the most negative environmental aspects of livestock production. It will be a truly Grand Challenge for animal scientists to meet these intersecting desires whilst simultaneously working with others to meet climate change goals and to conserve and restore wild habitats and biodiversity. Set within this context three broad challenges for animal scientists are outlined. The first will be to identify areas of work that have simultaneous and beneficial effects on the diverse issues that concern people. It will not be easy to find research areas that contribute holistically, but some positive examples are set out below (Challenge 1). Inevitably, however, there will be many situations where the pursuit of one objective threatens progress in another. An obvious example is how the on-farm benefits of using antimicrobials in terms of resource efficiency and farm income are outweighed by the concomitant increased risk of antimicrobial resistance for human health. The identification of this critical trade-off led the World Health Organization (2017) to call for a substantial and urgent reduction in the routine use of antimicrobials in animal production systems. In turn, this has stimulated a wealth of research into alternative methods of maintaining animal health and production (though there remains much to do; Redweik et al., 2020). Within the field of animal science, it is likely that many other unacknowledged more subtle trade-offs exist. A second challenge for researchers is therefore to identify, analyse and quantify these points of opposition and goal divergence (Challenge 2). A third challenge will be to understand better consumers' desires, knowledge and motivations. Sometimes citizens hold contradictory views about animal farming based on incomplete or inaccurate information, whilst scientists also lack insight into the attitudinal basis for consumer concerns. Dialogue and education that builds trust between different sectors of society, communities and stakeholders is needed to align goals for the future of animal science (Challenge 3).

Christine J. Nicol

cnico/@rvc.ac.uk

Received: 11 December 2020

Accepted: 12 January 2021

Published: 23 February 2021

Citation:

Nicol CJ (2021) A Grand Challenge for

Animal Science: Multiple Goals -

Convergent and Divergent.

Front. Anim. Sci. 2:640503

doi: 10.3389/fanim.2021.640503

\section{SETTING THE SCENE-THE ENVIRONMENTAL IMPACT OF LIVESTOCK PRODUCTION}

The adverse environmental effects of animal production can no longer responsibly be ignored, dismissed or left to future generations. The FAO's influential report, Livestock's Long Shadow (FAO, 2006), highlighted the effect of animal production on biodiversity loss and land use. Raising livestock also contributes to environmental pollution and generates a significant proportion of global greenhouse gas emissions. It is also inherently inefficient to transfer plant nutrients to humans via animals. Globally, $36 \%$ of the calories produced by crops are used for animal feed 
(Cassidy et al., 2013). In the face of a growing world population, many bodies now advocate that people in higher-income countries should reduce or replace their use of animal products to protect the environment. The International Panel on Climate Change (IPCC, 2019), for example, advocates a shift toward plant-based diets to reduce global warming. Scientific modeling reveals that if people in Europe replaced just half of their animalbased foods with plant-based foods (on a dietary energy basis) this would reduce nitrogen emissions by $40 \%$ and greenhouse gas emissions by $25-40 \%$ (Westhoek et al., 2014). Evidence of this kind has led some scientists to suggest that red meat should contribute no more than $5 \%$ to a normal diet (Machovina and Feeley, 2014). Even large meat-processing companies, fully aware of these trends, are investing heavily in plant-based alternatives (New York Times, 2019). Human diets may increasingly include protein from other resource-efficient sources, such as insects (Bessa et al., 2020) or, with further technological advances, from cultured animal cells.

However, farmed animals will not disappear from the planet anytime soon. Some groups of people in low and middle-income countries could benefit from consuming more animal-based protein and animals play an important practical or cultural role for many societies. There is much for the animal scientist to do, whether to ease a transition to an Eat Less, Eat Better future (RSPCA, 2018), or to improve access to high quality food for those in food poverty.

One important principle that underpins the involvement of animal science in debates about food policy and the environment, is that approaches that consider entire supply chains and all relevant environmental impacts must be employed. Debates can become skewed when single aspects (e.g., resource efficiency) are considered in isolation from others (e.g., land use), or when the efficiency of a farm is considered without measuring the origin and journey taken by the animal foodstuffs that may be imported. Life Cycle Assessment (LCA) is one such approach that allows scientists to consider animal management systems in the round. Using this methodology, Weeks et al. (2016) found that the main environmental burden associated with increased levels of laying hen mortality was the need to rear more replacement birds. Pelletier et al. (2010) used LCA to compare the resource efficiency, ecological footprint and emissions arising from different US beef production strategies. Environmental impacts were highest for pasture-finished beef and lowest in a system where calves were weaned to wheat pastures and then finished in feedlots. These results are not immediately intuitive and show the value of using an LCA approach to characterize relative environmental impacts.

\section{CHALLENGE 1-MULTIPLE, CONVERGENT, AND BENEFICIAL GOALS}

A positive example of the way that multiple goals are now being considered within animal science comes from the increasing use of breeding goals that encompass diverse and multi-faceted traits alongside the more traditional trait selection. A few selected examples will suffice to illustrate this point. By selecting animals for improved disease resistance (e.g., bovine TB, Tsairidou et al., 2018) productivity, environmental, and welfare goals are all simultaneously addressed. The realistic potential that Merino sheep could be selected for reduced susceptibility to flystrike (Brien et al., 2020) raises the possibility of ending the painful practice of "mulesing" (skin removal and scar formation around the breech area) and the widespread use of insecticides. Another promising, and less immediately obvious, trait for selection may be rumen microbial gene abundance, which could result in cattle that emit fewer greenhouse gases (Roehe et al., 2016). Genetic selection is also being used to increase animal lifespan, with the productive cycle of laying hens set to increase from 70 to 100 weeks (Fernyhough et al., 2019). Conjoint benefits of this strategy include the reduced environmental burden of raising replacement animals and avoidance of poor welfare associated with practices such as forced molting.

Animal geneticists are also developing increasingly imaginative approaches to address management problems such as injurious pecking in poultry. For example, quantifying natural variation in the beak shape of turkeys (Dalton et al., 2017 ) is the first step toward perhaps selecting birds with naturally blunter beaks that could be kept without the need for invasive beak-trimming procedures. The development of selection methodologies that include the social effects of one individual animal on the phenotypes of its companions will also become increasingly important as many countries move toward cage-free housing systems. An animal that is individually highly productive may nonetheless outcompete or show aggression to its companions reducing their welfare and overall group-level productivity (Ellen et al., 2014). A key challenge will be to ensure that selection does not lead to unintended negative consequences in any domain that has not been identified as a selection target and that animals remain in robust health.

Animal breeding is far from the only field where multiple, convergent goals can be identified. The use of ever more advanced technologies in disease surveillance and diagnosis can also produce holistic and synergistic benefits. Nano-, molecular and engineering technologies will increasingly be deployed in rapid and non-invasive farm-side detection and diagnosis of animal diseases (e.g., Bannerjee and Jaiswal, 2018; Gupta et al., 2019). The increasing application of advanced technology in automated monitoring platforms will also provide early warnings of health or welfare problems arising at a flock or herd level, for instance shifts in broiler flock movement patterns detected using optical flow patterns can signal early signs of flock infection with campylobacter (Colles et al., 2016). Alongside enhanced surveillance comes the opportunity to prevent or even eradicate disease threats from whole populations through the development and use of effective vaccinations. An ultimate challenge might be an accelerated programme of animal disease eradication. To date, the only animal disease that has been globally eradicated is rinderpest, but the International Task Force for Disease Eradication (ITFDE) has identified Cysticercosis as a potentially eradicable foodborne disease. The ITFDE postulated that vaccination could play a role, but profound challenges arise when designing vaccines that are effective for parasites with complex lifecycles (Sander et al., 2020) and 


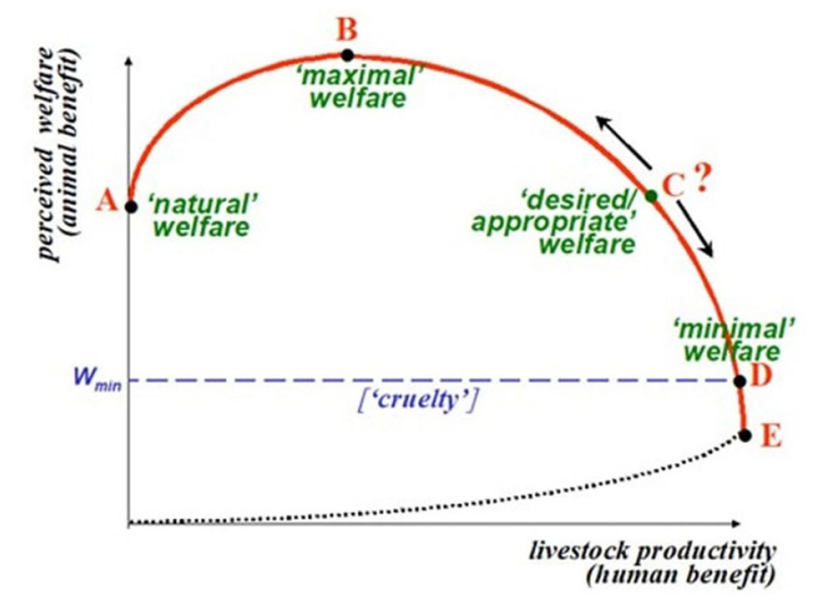

FIGURE 1 | A curved function illustrates a proposed relationship between livestock productivity and animal welfare (from Mclnerney, 2004).

so surveillance and a better understanding of transmission pathways may turn out to be more effective strategies to counter this disease.

\section{CHALLENGE 2-DIVERGENT GOALS AND TRADE-OFFS}

A critical role for animal science will be to provide the evidence to quantify areas where trade-offs exist to enable policy makers to make decisions, sometimes drastic (phasing out antimicrobials) but sometimes nuanced. An area where further work is needed is in assessing real and perceived trade-offs between livestock productivity and animal welfare (see Figure 1).

Point A is considered as an initial reference where no specific management effort is invested (e.g., backyard chicken keeping). As improved animal management and disease control measures are implemented, joint gains in productivity and welfare are usually observed, taking us toward point B. But beyond this point, efforts to increase productivity (for example by increasing stocking density or selecting for more rapid growth) occur at the expense of individual animal welfare (e.g., Ahmed et al., 2020). This model has been influential but intuitions about the effects of different management interventions are not always correct and animal science is needed to identify the real interactions between productivity, health and animal welfare. For example, improved animal health is not always associated with improved efficiency of production. In a study of dairy farm efficiency in Denmark, it was found that the most efficient dairy farms had higher levels of lameness, ketosis and digestive disorders (Lawson et al., 2004). These farms tended to resort to early culling, high replacement rates, and enrolling heifers in production at an earlier age with shorter calving intervals, placing high demands on young cows, who experience high disease levels and a short life expectancy. In this case, more efficient production was associated with reduced animal health (and welfare), visualized in Figure 1 as a move from point B to C. Another counterintuitive example is that adherence to strict welfare guidelines does not always lead to a reduction in productivity. Danish pig producers that met all animal regulations (assessed during unannounced visits) also achieved a (slightly) higher overall farm efficiency than farms where regulations were sometimes breached (Henningsen et al., 2018). Scientific analysis may also show that assumptions about apparently inevitable trade-offs may be misplaced. For example, the high prevalence of leg disorders in broiler chickens (Knowles et al., 2008) has led to calls for the use of slower-growing breeds to improve animal welfare, but such a move would (perhaps greatly) lower the efficiency of chicken production. This appears at first sight to be an irrefutable conflict but Dawkins and Layton (2012) argue that although there are correlations between rapid growth and lameness in current commercial strains of chicken, this is not an inevitable correlation. They point out that many wild birds have very high juvenile growth rates without negative health effects and suggest that selection that targets improved skeletal health could allow the development of fast-growing birds with good welfare.

Another area where potential trade-offs abound relates to the impact of animals on land use and biodiversity. Balmford et al. (2012) have argued that farming, and particularly livestock production, is more damaging to wild nature than any other human activity and they have set out a clear policy direction to address this, strongly advocating a Land Sparing approach. This would encourage the intensification of food production per unit area to ensure that pristine areas are protected and designated for habitat conservation or restoration, predicated on the idea that many wild species simply cannot exist within humanmanaged agricultural systems (Phalan et al., 2016). However, a fundamentally opposing Land Sharing model proposes that biodiversity should be encouraged within less-intensive ecoagricultural systems that better protect animal welfare and rural communities. There are multiple trade-offs that require further study to solve this conundrum. Even the apparently sensible suggestion that ruminants should be produced primarily in areas where they can make use of grass, hay or forage of little direct use to humans to improve livestock sustainability (Eisler et al., 2014) has been challenged. The very inefficiency of forage-based systems means that, under this approach, a high proportion of land would be allocated to livestock, to the detriment of efforts to restore true biodiversity (zu Ermgassen et al., 2014). Balmford et al. (2012) entitled their paper "What Conservationists need to know about farming" which prompts the suggestion that future animal scientists will need to know more about conservation. Together we need to establish which wild species can co-exist with livestock, and whether truly biodiverse managed environments can be created. Animal scientists have a role to play in facilitating a transition that lowers overall global consumption of animal products, enables sustainable land sharing and ensures more equitable distribution of animal-based foods. One solution will not fit all circumstances and in certain regions of the world, animal scientists may need 
to work out how to intensify production without detriment to animal welfare.

\section{CHALLENGE 3-SHARING KNOWLEDGE AND ALIGNING GOALS BETWEEN SECTORS OF SOCIETY}

A third challenge is that animal scientists will need to research, understand, and address the knowledge gap that can exist between consumers, producers, and scientists. Citizens in highincome countries tend to have a negative view of industrial agriculture and an all-encompassing positive view of farming systems that are perceived as natural (Bray and Ankeny, 2017; Ochs et al., 2019). For example, consumers have very positive views about free-range systems for laying hens, not just in relation to the behavioral freedom they incontrovertibly provide for birds, but also for attributes that they patently do not possess, such as a lower risk of disease. Some consumers view freerange systems as posing a lower risk of avian influenza, even though the science shows this disease is primarily transmitted via outdoor contact with wild birds (van Asselt et al., 2018). Misunderstandings can produce paradoxical demands e.g., for high welfare food from systems that pose high health risks to animals. The need for further dialogue comes from studies showing that many consumers rate access to outdoor air as more important for laying hens than space allowance (Pettersson et al., 2016) and that negative views about farming practices sometimes sit alongside a lack of awareness of animal welfare advances that have been achieved (Sonntag et al., 2019). Healthy animals can be housed in large numbers in high welfare systems with low environmental impact (e.g., the Windstreek broiler farm; https://www.windstreek.eu/) but such developments must appeal to consumers. Automated production systems using novel technical monitoring and robotic handling procedures also have the potential to improve farming efficiency and animal welfare but may be negatively perceived by people who are already skeptical about industrialized agriculture. Greater understanding of how cultural background and media exposure influence the development of attitudes toward animals and food production will be needed to align scientific progress with consumer acceptance.

\section{AUTHOR CONTRIBUTIONS}

The author confirms being the sole contributor of this work and has approved it for publication.

\section{REFERENCES}

Ahmed, H., Alvasen, K., Berg, C., Hansson, H., Hultgren, J., Rocklinsberg, H., et al. (2020). Assessing economic consequences of improved animal welfare in Swedish cattle fattening operations using a stochastic partial budgeting approach. Livestock Sci. 232:e103920. doi: 10.1016/j.livsci.2020.103920

Balmford, A., Green, R., and Phalan, B. (2012). What conservationists need to know about farming. Proc. R. Soc. $B$ 279, 2714-2724. doi: $10.1098 / \mathrm{rspb} .2012 .0515$

Bannerjee, R., and Jaiswal, A. (2018). Recent advances in nanoparticle-based lateral flow immunoassay as a point-of-care diagnostic tool for infectious agents and diseases. Analyst 143, 1970-1996. doi: 10.1039/c8an00307f

Bessa, L. W., Pieterse, E., Sigge, G., and Hoffman, L. C. (2020). Insects as human food; from farm to fork. J. Sci. Food Agric. 100, 5017-1022. doi: $10.1002 /$ jsfa. 8860

Bray, H. J., and Ankeny, R. A. (2017). Happy chickens lay tastier eggs: motivations for buying free-range eggs in Australia. Anthrozoos 30, 213-226. doi: 10.1080/08927936.2017.1310986

Brien, F. D., Walkom, S. F., Swan, A. A., and Brown, D. J. (2020). Substantial genetic gains in reducing breech flystrike and in improving productivity traits are achievable in Merino sheep by using index selection. Anim. Product. Sci. doi: 10.1071/AN20248. [Epub ahead of print].

Cassidy, E. S., West, P. C., Gerber, J. S., and Foley, J. A. (2013). Redefining agricultural yields: from tonnes to people nourished per hectare. Environ. Res. Lett. 8:e034015. doi: 10.1088/1748-9326/8/3/034015

Colles, F. M., Cain, R. J., Nickson, T., Smith,A. L., Roberts, S. J., Maiden, M. C. J., et al. (2016). Monitoring chicken flock behaviour provides early warning of infection by human pathogen Campylobacter. Proc. R. Soc. B Biol. Sci. 283:e20152323. doi: 10.1098/rspb.2015.2323

Dalton, H. A., Wood, B. J., Widowski, T. M., Guerin, M. T., and Torrey, S. (2017). An analysis of beak shape variation in two ages of domestic turkeys (Meleagris gallopavo) using landmark-based geometric morphometrics. PLoS ONE:e0185159. doi: 10.1371/journal.pone.0185159

Dawkins, M. S., and Layton, R. (2012). Breeding for better welfare: genetic goals for broiler chickens and their parents. Ani. Welfare 21, 147-155. doi: $10.7120 / 09627286.21 .2 .147$

Eisler, M. C., Lee, M. R. F., Tarlton, J. F., Martin, G. B., Beddington, J., Dungait, J. A. J., et al. (2014). Steps to sustainable livestock. Nature 507, 32-34. doi: $10.1038 / 507032$ a

Ellen, E. D., Rodenburg, T. B., Albers, G. A. A., Bolhuis, J. E., Camerlink, I., Duijvesteijn, N., et al. (2014). The prospects of selection for social genetic effects to improve welfare and productivity in livestock. Front. Genet. 5:e377. doi: 10.3389/fgene.2014.00377

FAO (2006). Livestock's Long Shadow. Available online at: http://www.fao.org/3/ a0701e/a0701e00.htm (accessed February 11, 2021).

Fernyhough, M., Nicol, C. J., van de Braak, T., Toscano, M. J., and Tønnessen, T. (2019). The ethics of laying hen genetics. J. Agric. Environ. Ethics 33, 15-36. doi: 10.1007/s10806-019-09810-2

Gupta, N., Renugopalakrishnan, V., Liepmann, D., Paulmurugan, R., and Malhotra, B. D. (2019). Cell-based biosensors: recent trends, challenges and future perspectives. Biosens. Bioelectr. 141:e111435. doi: 10.1016/j.bios.2019.111435

Henningsen, A., Czekaj, T. G., Forkman, B., Lund, M., and Nielsen, A. S. (2018). The relationship between animal welfare and economic performance at farm level: a quantitative study of Danish pig producers. J. Agric. Econ. 69, 142-162. doi: 10.1111/1477-9552.12228

IPCC (2019). Table 6.10. Available online at: https://www.ipcc.ch/srccl/ (accessed February 11, 2021).

Knowles, T. G., Kestin, S. C., Haslam, S. M., Brown, S. N., Green, L. E., Butterworth, A., et al. (2008). Leg disorders in broiler chickens: prevalence, risk factors and prevention. PLOS ONE 3:e1545. doi: 10.1371/journal.pone. 0001545

Lawson, L. G., Agger, J. F., Lund, N., and Coelli, T. (2004). Lameness, metabolic and digestive disorders and technical efficiency in Danish dairy herds: a stochastic frontier production function approach. Livestock Product. Sci. 91, 157-173. doi: 10.1016/j/livprodsci/2004/07/016

Machovina, B., and Feeley, K. J. (2014). Livestock:limit red meat consumption. Nature 508:186. doi: 10.1038/508186c

McInerney (2004). Animal Welfare, Economics and Policy. Available online at: https://webarchive.nationalarchives.gov.uk/20110318142209/http:/ www.defra.gov.uk/evidence/economics/foodfarm/reports/documents/ animalwelfare.pdf (accessed February 11, 2021). 
New York Times (2019). Available online at: https://www.nytimes.com/2019/10/ 14/business/the-new-makers-of-plant-based-meat-big-meat-companies.html (accessed February 11, 2021).

Ochs, D., Wolf, C. A., Widmar, N. J., and Bir, C. (2019). Is there a "cage-free" lunch in US egg production? Public views of laying-hen housing attributes. J. Agric. Resour. Econ. 44, 345-361. doi: 10.22004/ag.econ.287982

Pelletier, N., Pirog, R., and Rasmussen, R. (2010). Comparative life cycle environmental impacts of three beef production strategies in the Upper Midwestern United States. Agric. Syst. 103, 380-389. doi: 10.1016/j.agsy.2010.03.009

Pettersson, I. C., Weeks, C. A., Wilson, L. R. M., and Nicol, C. J. (2016). Consumer perceptions of free-range laying hen welfare. Br. Food J. 118, 1979-1993. doi: 10.1108/BFJ-02-2016-0065

Phalan, B., Green, R. E., Dicks, L. V., Dotta, G., Feniuk, C., Lamb, A., et al. (2016). How can higher-yield farming help to spare nature? Science 351, 450-451. doi: 10.1126/science.aad0055

Redweik, G. A. J., Jochum, J., and Mellata, M. (2020). Live bacterial prophylactics in modern poultry. Front. Vet. Sci. 7:e592312. doi: 10.3389/fvets.2020.592312

Roehe, R., Dewhurst, R. J., Duthie, C. A., Rooke, J. A., McKain, N., Ross, D. W., et al. (2016). Bovine host genetic variation influences rumen microbial methane production with best selection criterion for low methane emitting and efficiently feed converting hosts based on metagenomic gene abundance. PLoS Genet. 12:e1005846. doi: 10.1371/journal.pgen.1005846

RSPCA (2018). Available online at: https://www.eating-better.org/blog/rspcaassured-launches-eat-less-eat-better-campaign\#:।sim:text=Eating\%20Better \%20has\%20welcomed\%20a, only\%20choose\%20higher\%20welfare\%20labels (accessed February 11, 2021).

Sander, V. A., Lopez, E. S. F., Morales, L. M., Duarte, V. R. A., Corigliano, M. G., and Clemente, M. (2020). Use of veterinary vaccines for livestock as a strategy to control foodborne parasitic diseases. Front. Cell. Infect. Microbiol. 10:e288. doi: $10.3389 /$ fcimb. 2020.00288

Sonntag, W. I., Spiller, A., and von Meyer-Hfer, M. (2019). Discussing modern poultry farming systems insights into citizen's lay theories. Poultry Sci. 98, 209-216. doi: 10.3382/ps/pey292
Tsairidou, S., Allen, A., Banos,G., Coffey, M., Anacleto, O., Byrne, A. W., et al. (2018). Can we breed cattle for lower Bovine TB infectivity. Front. Vet. Sci. 5:e310. doi: 10.3389/fvets.2018.00310

van Asselt, M., Poortvliet, P. M., Ekkel, E. D., Kemp, B., and Stassen, E. N. (2018). Risk perceptions of public health and food safety hazards in poultry husbandry by citizens, poultry farmers and poultry veterinarians. Poultry Sci. 97, 607-619. doi: $10.3382 / \mathrm{ps} / \mathrm{pex} 325$

Weeks, C. A., Lambton, S. L., and Williams, A. G. (2016). Implications for welfare, productivity and sustainability of the variation in reported levels of mortality for laying hen flocks kept in different housing systems: a metaanalysis of ten studies. PLoS ONE 11:e0146394. doi: 10.1371/journal.pone. 0146394

Westhoek, H., Lesschen, J. P., Rood, T., Wagner, S., De Marco, A., MurphyBokern, D., et al. (2014). Food choices, health and environment: effects of cutting Europe's meat and dairy intake. Glob. Environ. Change Hum. Policy Dimensions 26, 196-205. doi: 10.1016/j/gloenvcha.2014. 02.004

World Health Organization (2017). Available online at: https://www.who.int/ foodsafety/areas_work/antimicrobial-resistance/cia_guidelines/en/ (accessed February 11, 2021).

zu Ermgassen, E. K. H. J., Williams, D. R., and Balmford, A. (2014). Livestock:tackle demand and yields. Nature 508:186. doi: 10.1038/ $508186 \mathrm{~b}$

Conflict of Interest: The author declares that the research was conducted in the absence of any commercial or financial relationships that could be construed as a potential conflict of interest.

Copyright (c) 2021 Nicol. This is an open-access article distributed under the terms of the Creative Commons Attribution License (CC BY). The use, distribution or reproduction in other forums is permitted, provided the original author(s) and the copyright owner(s) are credited and that the original publication in this journal is cited, in accordance with accepted academic practice. No use, distribution or reproduction is permitted which does not comply with these terms. 